\title{
Symposium review: An abundance of replacement heifers: What is the economic impact of raising more than are needed?*
}

\section{W. Overton† $₫$ and K. C. Dhuyvetter \\ Elanco Animal Health, Greenfield, IN 46140}

\section{ABSTRACT}

Historically, most dairy producers raised every heifer born, to ensure a supply of future replacements. However, advancements in transition and reproductive management, coupled with widespread use of sexsorted semen in dairy heifers and cows, have led to an oversupply of dairy replacement heifers in the United States. With current market values for prepartum heifers at $\$ 1,300$ and estimated raising costs ranging from $\$ 1,700$ to $\$ 2,400$, dairies that continue to produce quantities of heifers in excess of anticipated needs with plans of selling the extras on the open market are likely to experience significant economic loss. Adult cow herd turnover is the key driver behind the number of heifers needed to calve; however, mortality, disease, fertility, and elective culling losses throughout the heifer-raising period determine the total number of heifers that must be retained and raised to meet anticipated needs. A convenience sample of 50 US dairy herds revealed an average heifer inventory of $102 \%$ of total milking and dry cows. In this data set, the mean annualized adult herd turnover was 39\%. With a mean stillbirth risk of $5.7 \%$ in calving heifers, a culling risk of $10.2 \%$ by 13 mo of age, a reproductive failure risk of $6.8 \%$ in breeding heifers, and an additional culling risk of $6.4 \%$ in pregnant heifers, only $74 \%$ of calving events with a heifer birth yielded a heifer that entered the lactating herd. Much of this heifer removal was elective, and making the correct culling decisions at the appropriate time yields the best return for the herd. To demonstrate how a herd might approach the elective culling issue, a records-based exercise with 2 large Holstein herds was performed to estimate the cost versus benefit of 3 different elective culling approaches, using a combination of genetic potential and growth performance as the selective criteria. However, the culling of heifers results

Received June 22, 2019.

Accepted December 4, 2019.

*Presented as part of the Southern Section Symposium: Dairy Cattle Longevity Revisited-Trends, Economics, and Opportunities, at the ADSA Annual Meeting, Cincinnati, Ohio, June 2019.

†Corresponding author: moverton@elanco.com in economic losses, because the revenue received is less than the cost incurred during raising. Selective culling of heifers soon after weaning yielded the best results in both herds, but despite the predicted improvement in lactation performance of the retained group, the cost associated with removal was greater than the benefit predicted. Culling a group early and then culling a second group just before calving yielded the largest loss. Moving forward, herds should breed more carefully to produce better-quality heifers from more superior dams and sires and consider the use of beef semen in inferior animals. However, to reduce the risk of not producing an adequate supply of replacement heifers, dairies should add an additional buffer to their anticipated needs. Using the assumptions within this project, having $10 \%$ extra calving events with a heifer birth would allow the annualized adult herd turnover to rise from 39 to $43 \%$ in case economic conditions or health status of the herd should change. If these heifers are not needed, the selection criteria outline could be used to help identify more valuable animals to retain.

Key words: replacement heifers, herd turnover, culling

\section{INTRODUCTION}

Historically, most dairy producers raised every heifer calf born alive on the farm, to ensure an adequate supply of replacements. Cows and heifers were inseminated with semen from dairy sires, and reproductive performance often failed to provide a sufficient number of replacement animals to meet anticipated needs when annualized herd turnover exceeded 30 to $35 \%$. Advancements in transition and reproductive management, coupled with more genetic selection focused on fertility, have yielded large improvements in dairy reproductive performance over the past decade. Additionally, many herds have adopted the widespread use of sex-sorted semen in dairy heifers and, to a lesser extent, in lactating cows. Consequently, many producers find themselves with an oversupply of dairy replacement heifers relative to anticipated herd needs.

An oversupply of replacement heifers for an individual farm can be both a benefit and a liability. A large 
heifer inventory historically was viewed as an indication of a healthy, prosperous dairy; it provided a sense of assurance or abundance for the dairy owner. Excess heifers ensured an adequate supply from which to select herd replacement animals and served as a marketable asset that could be sold to generate operating capital. However, a surplus on farm of replacement heifers today has contributed to economic strain for many dairies. Raising costs, including capital investments, animal value, opportunity costs of each investment, and costs incurred by heifers that fail to survive to calving, commonly range from $\$ 1,700$ to over $\$ 2,400$ (Overton et al., 2013; Karszes, 2014; Overton and Dhuyvetter, 2017; Tranel, 2019). Unfortunately for producers with extra heifers to sell, current market values average approximately $\$ 1,300$, based on a survey of dairy auction markets (https://www.progressivedairy.com/news/ organizations/market-watch-cattle). Although many factors interact to affect the value of heifers, the potential of widespread adoption of sex-sorted semen from dairy sires, as opposed to other sire selection options, to depress replacement heifer market values was discussed over a decade ago (Fetrow et al., 2007; De Vries et al., 2008).

Culling is the removal of cows from the herd due to sale, slaughter, salvage, or death. Herd turnover is defined as the number of cows (milking and dry) culled over 12 mo divided by the average population of cows at risk (milking and dry) for that same time (Fetrow et al., 2006). Trends for longevity or stayability have generally been negative since 1965, with periods of flattening or no change (Everett et al., 1976; Nieuwhof et al., 1989; Hadley et al., 2006). In the last decade, observations by the authors from many commercial dairy herds reflect typical herd turnover levels of 35 to $40 \%$, at times reaching 45 to $50 \%$, compared with historical levels of 25 to $30 \%$. However, culling, per se, is not and should not be used as an indication of excessive mortality, poor health, or low fertility. Although these factors do contribute to culling, in modern dairy herds with improved management, culling is also highly reflective of economic factors such as milk price, replacement price, and cull cow values, as well as other important drivers such as genetic improvement, reproductive performance, and heifer availability. Culling, when performed appropriately, is the process of improving the herd by replacement, and decisions to replace should be made with a focus on continuous improvement.

Under most economic conditions, cows removed from the herd due to mortality, disease, infertility, or low milk production, or sold for dairy purposes, should be replaced immediately to keep facilities full, so as to dilute fixed costs. Therefore, the primary factor influencing herd turnover is the availability of replacement heifers, either raised on the farm or purchased, and the cost versus the projected benefit of replacement. If more replacement heifers are available, herds must decide whether to sell these heifers or calve them, and if herd numbers are stable, an existing cow must leave to make room for an incoming replacement. Although the most common replacement is a newly calved primiparous cow, replacements might also include purchased mature cows, but for the remainder of this paper, the focus will be on farm-raised primiparous replacements.

Historic farm-level herd turnover risks are a logical starting point for predicting replacement needs, but they do not account for unanticipated health or fertility problems, or for economic opportunities to improve the herd. Herd turnover is costly, but failing to cull cows at the appropriate time is also costly. Producers are often reluctant to purchase replacements, whether due to financial or other reasons, and if insufficient replacements are available on farm, opportunity costs occur from the delay in replacement of poor-performing cows. Aside from the anticipated herd turnover, other factors affecting the heifer population and replacement needs include semen choice (conventional, sex-sorted, or beef), abortion risk, stillbirth risk, culling risk of pregnant animals, heifer mortality risk, heifer reproductive efficiency, heifer abortion risk, and heifer growth rate.

Advancements in dairy breeding and selection have created both opportunities and challenges. Sex-sorted semen has been widely adopted, primarily among nulliparous heifers but also, to a lesser extent, among lactating cows. Farms now have the choice of using sex-sorted semen, conventional semen, or semen from beef sires, depending on the predicted value of the animal being inseminated, replacement heifer needs, and projected calf values. A less widely used but growing management option is embryos derived from in vitro fertilization. Genomic testing, ideally coupled with growth performance analyses, is one tool that has been adopted to help differentiate animals for both breeding and culling purposes. Whether through sire selection, dam selection, or, ideally, both, producers are able to create superior replacement heifers from superior animals and more valuable beef or beef-cross calves from genetically inferior animals by careful matching of dams and sires, while still meeting their herds' replacement needs.

Raising a modest excess of heifers over anticipated needs can be viewed as a form of risk management, or "insurance," that sufficient replacements will be available as needed. However, calving all heifers simply because they have been raised by the farm and disregarding true replacement needs results in the premature culling of otherwise productive cows to make room in the herd. This action results in a higher-than-optimal 
herd turnover and economic losses. As previously described, under current market conditions, the cost of raising replacement heifers is greater than the market value of springers, and thus the culling of excess heifers results in a financial loss. Because of this, it may be economically advantageous to cull excess heifers earlier and thus eliminate or reduce the cost of raising them. Proper and timely culling decisions, using both predicted genetic values and growth performance, can reduce capital requirements, lower future economic loss, and increase the net value of heifers entering the milking herd. The many sire and reproductive management options, coupled with potentially large inventories of lower-valued replacement heifers in utero or on farm have producers asking how many heifers they really need, which animals should produce replacements, and what to do with excess heifers.

\section{FACTORS INFLUENCING REPLACEMENT NEEDS}

Every dairy herd has an optimal capacity for milking and dry cows, given the existing unique constraints for that dairy. Assuming that the herd is neither expanding nor contracting, as cows leave the herd due to low milk production, disease, lameness, infertility, being sold to another dairy, or any other reason, replacements should enter the herd to occupy the vacated space in a timely fashion to most efficiently dilute the fixed costs of housing, milking equipment, utilities, insurance, and more. Another way to examine culling and replacement is that as a replacement animal becomes available, an existing cow may be removed. Thus, replacement heifer availability and herd turnover are aligned.

Working from the assumption that a herd is neither expanding nor contracting and will use home-grown heifers, the number of replacements needed to calve per year is equivalent to the anticipated number of cows that will be culled. However, the heifer that calves today began her journey from conception to birth to heifer growth and development approximately 2.5 to 3 years prior. Factors such as stillbirth risk, mortality risk, reproductive efficiency, and culling risk combine to determine the total number of heifers needed along the way.

To examine the magnitude of these factors, we collected a convenience sample of 50 Holstein herds from across the United States. For each herd, a copy of the on-farm record system (DairyComp 305, Valley Agricultural Software Inc., Tulare, CA) was obtained, with backup dates ranging from December 2018 through January 2019. Median total herd size for milking and dry cows was 2,410, with a range of 249 to 13,602 . Herd-level milk production averaged $39.0 \mathrm{~kg} / \mathrm{cow}$ per day, with a range of 29.7 to 47.4 , and 305-d mature- equivalent (305ME) milk yield averaged 12,809 kg, with a range of 10,856 to 15,426 . Herd turnover was calculated for each herd for the most recent $12 \mathrm{mo}$ and averaged $40 \%$ (range of 28 to $51 \%$ ) including all animals sold or died, and 39\% (range of 25 to $51 \%$ ) when excluding animals sold for dairy purposes.

Replacement heifer completion metrics were calculated using records from heifers born between 850 and $1,200 \mathrm{~d}$ before the farm backup date, to allow ample follow up time for heifers to calve into the herd. An age of 13 mo was used as a proxy for reaching breeding age. For each farm, the following replacement heifer metrics were estimated and are reported in Table 1:

- $\%$ Heifers born alive $=1-$ recorded still birth incidence

- \% Sold before $13 \mathrm{mo}=\%$ of heifers born alive that had a removal date but no death code recorded, before reaching $13 \mathrm{mo}$ of age

- \% Dead before $13 \mathrm{mo}=\%$ of heifers born alive that had both a removal date and a death code recorded before 13 mo of age

- \% Survival to $13 \mathrm{mo}=\%$ of heifers born alive that did not have a removal date recorded before reaching 13 mo of age

- $\%$ Heifers over 13 mo that conceived $=\%$ of heifers that reached 13 mo of age that had a recorded conception date

- \% Pregnant heifers that calved $=\%$ of heifers with a recorded conception date and a subsequent calving date

- \% Calving events with a heifer birth that goes on to calve $=\%$ of heifer births (alive or dead) that resulted in a subsequent calving event

To illustrate the influence of these metrics on replacement heifer needs, the mean results were applied to a hypothetical herd with 1,000 milking and dry cows that has an annual turnover of $39 \%$, which includes cows that were replaced for any reason. For this herd, 390 cows were culled within a year; thus, 390 replacements are needed to calve within the same year. Table 2 applies the results from Table 1 to this hypothetical example, proceeding from birth through growth, reproduction, and finally parturition.

\section{CONSEQUENCES OF NOT OPTIMIZING REPLACEMENT NUMBERS}

Good dairy preventive medicine emphasizes management practices that improve the health, productivity, and welfare of cows and lowers the risk of cows losing value sufficiently to warrant premature culling. However, this is not the same as saying that lower herd turnover 
Table 1. Herd-level means, SD, and 95\% CI from the 50-herd data set for replacement heifer metrics

\begin{tabular}{lrcc}
\hline Item & Mean & SD & $95 \%$ CI \\
\hline \% Heifers born alive & 94.3 & 0.51 & $93.2-95.3$ \\
\% Survival to 13 mo & 89.8 & 0.81 & $88.1-91.4$ \\
\% Sold before 13 mo & 4.2 & 0.75 & $2.7-5.7$ \\
\% Dead before 13 mo & 6.0 & 0.47 & $5.1-7.0$ \\
\% Heifers over 13 mo that conceived & 93.2 & 0.57 & $92.1-94.4$ \\
\% Pregnant heifers that calved & 93.6 & 0.69 & $92.3-95.0$ \\
\% Calving events with a heifer birth that calved & 73.9 & 1.00 & $71.8-76.0$ \\
\hline
\end{tabular}

is always best. Once a cow has dropped sufficiently in value to warrant removal, regardless of the reason, appropriate and timely culling with replacement is critical to maximize economic returns. If there are insufficient home-raised replacement animals available, cash flow constraints, heifer supply limitations, or disease risk concerns that preclude purchasing replacements, herd turnover will be lower than ideal, resulting in prolonged retention of economically inferior cows and a lower average milk production per cow per day. However, if the replacement pool is excessively large and all surviving heifers calve and enter the herd, herd turnover might be excessive, resulting in higher replacement costs and lower milk production per cow per day. Each culling decision should be an individual cow decision, based upon the existing cow's current and projected value of staying in the herd versus the projected net value (income over feed cost minus replacement cost) of the replacement animal. Thus, economically optimal culling decision-making requires a delicate balance between maintaining an adequate, but not excessive, replacement pool from which to choose, and the producer's financial ability and willingness to purchase appropriate replacements as needed, should the on-farm supply be inadequate.

As previously stated, at the time of writing (July 2019), the value of good-quality prepartum heifers that are ready to calve is $\$ 1,300$, but the actual cost to raise a dairy replacement to calving is considerably higher.
Current values for feed inputs, housing costs, and reproductive management needs were entered into a heifer raising cost model (Overton et al., 2013). Assuming a newborn calf value of $\$ 60$, a targeted breeding weight that is $57 \%$ of mature cow weight, a mature weight of $725 \mathrm{~kg}$, labor at $\$ 15$ per $\mathrm{h}$, and a capital cost of $6 \%$, the estimated total cost to raise a Holstein replacement varies from approximately $\$ 1,700$ to $\$ 2,400$, depending upon labor efficiencies (calf ranch vs. large dairy vs. small dairy), confinement versus extensive housing, and feeding strategies. The current projected cost for raising heifers in a large dairy using primarily confinement housing from birth through calving is currently $\$ 2,016$ (Table 3) given the feeding and management assumptions used. This cost is on a "per surviving heifer" basis and includes the opportunity costs of each investment, the wet calf initial value, and the costs incurred by heifers that fail to survive to calving. In this baseline scenario, the only culls beyond mortality are reproductive culls - heifers that failed to conceive or that aborted.

In current market conditions, producers that cull heifers into the beef market incur significant losses, because market values fail to cover the full investment costs. Estimates of the magnitude of these losses are shown in Table 4 . The beef values for each stage represent the average values obtained from online market news reports from public auction houses located in California (escalonlivestockmarket.com), Pennsylvania (https:/ /mymarketnews.ams.usda.gov/filerepo/reports), Mis-

Table 2. Anticipated herd culling and replacement needs, assuming a static herd size, estimated in a stepwise manner using the mean metrics reported in Table 1

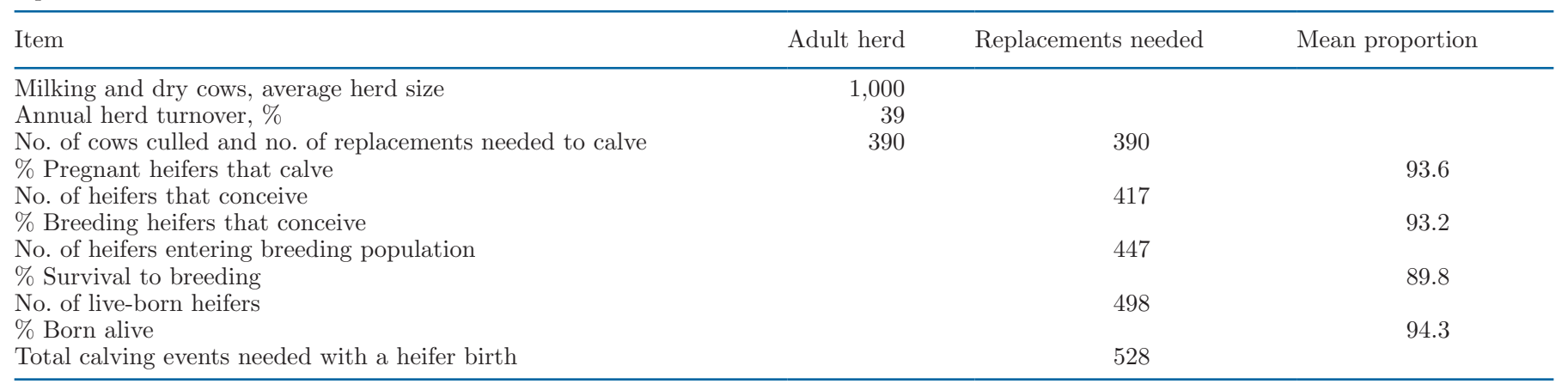


Table 3. Estimated cost per stage for replacement heifer raising, assuming a $\$ 60$ newborn value, $6 \%$ cost of capital, liquid preweaning diet based on feeding a 28:18 milk replacer, and confinement housing and feeding ${ }^{1}$

\begin{tabular}{|c|c|c|c|c|c|c|}
\hline \multirow[b]{2}{*}{ Item } & \multicolumn{6}{|c|}{ Stage } \\
\hline & Hutch & Postweaning & Growing & Breeding & Postbreeding & Close-up \\
\hline Mortality, \% & 3.50 & 1.75 & 1.00 & 0.50 & 0.30 & 0.25 \\
\hline Culled (sold), \% & 0.0 & 0.0 & 0.0 & 0.0 & 7.0 & 0.0 \\
\hline \multicolumn{7}{|l|}{ Costs, $\$ /$ head } \\
\hline Colostrum & 16 & & & & & \\
\hline Grain & & 71 & & & & \\
\hline Forage & & 5 & & & & \\
\hline Feed (TMR) & & & 217 & 262 & 311 & 153 \\
\hline Total feed & 205 & 76 & 217 & 262 & 311 & 153 \\
\hline Labor & 48 & 10 & 12 & 33 & 14 & 30 \\
\hline Vet med/health & 18 & 5 & 8 & 3 & 3 & 15 \\
\hline Breeding and culls & & & & 35 & $(61)$ & \\
\hline Exit weight, $\mathrm{kg}$ & 90 & 148 & 319 & 470 & 608 & 655 \\
\hline $\mathrm{ADG}, \mathrm{kg}$ & 0.79 & 0.98 & 0.94 & 0.87 & 0.81 & 0.76 \\
\hline Cumulative ADG, kg & 0.79 & 0.88 & 0.92 & 0.90 & 0.87 & 0.86 \\
\hline \multicolumn{7}{|l|}{ Cumulative from birth } \\
\hline Total cost, $\$ /$ head & 303 & 421 & 749 & 1,178 & 1,663 & 1,938 \\
\hline Cost/day, $\$ /$ head per day & 4.81 & 3.46 & 2.46 & 2.46 & 2.56 & 2.73 \\
\hline Cost including wet calf, $\$ /$ head & 366 & 486 & 816 & 1,248 & 1,740 & 2,016 \\
\hline
\end{tabular}

${ }^{1}$ Cost estimates include the opportunity costs of each investment and the costs incurred by heifers that fail to survive to calving. The cost including wet calf is the total cost plus the initial investment for the wet calf.

souri (producerslivestock.com), and Idaho (https:// mymarketnews.ams.usda.gov/filerepo/reports) that reported values for heifers across a range of body weights. Using the assumed market values per $\mathrm{kg}$ of live weight for culled heifers and their estimated weight at each management stage of the model, we find significant losses incurred with culling, and the magnitude of these losses increases as the age at culling increases. In the past, the value of a prepartum heifer has at times been great enough to recoup the investment cost and make a slight profit, but that is not the case under current market conditions.

\section{A MANAGEMENT OPTION FOR EXCESSIVE REPLACEMENTS}

What options exist for herds that find themselves with more heifers in their replacement pipeline than they anticipate needing? First, alternative breeding options are increasingly being adopted to reduce the likelihood of significant future oversupply: for instance, increased use of conventional beef semen or, to a lesser extent, sexed beef semen favoring the production of male crossbred calves. However, this does nothing to alleviate the currently unprofitable situation associated

Table 4. Heifer raising cost details by stage (age in months) and corresponding economic values based on timing of culls

\begin{tabular}{|c|c|c|c|c|c|c|}
\hline \multirow[b]{2}{*}{ Item } & \multicolumn{6}{|c|}{ Stage, starting age to ending age, mo } \\
\hline & $0.0-2.0$ & $2.1-4.0$ & $4.1-10.0$ & $10.1-15.7$ & $15.8-21.4$ & $21.5-23.4$ \\
\hline Total cost for heifer completing stage, $\$ /$ head & 366 & 486 & 816 & 1,248 & 1,740 & 2,016 \\
\hline Weight of cull, $\mathrm{kg}$ & & 104 & 161 & 345 & 519 & 619 \\
\hline Beef value, ${ }^{1} \$ / \mathrm{kg}$ & & 2.10 & 1.84 & 1.79 & 1.75 & 1.98 \\
\hline Beef value, $\$ /$ head & & 218 & 295 & 618 & 907 & 1,175 \\
\hline
\end{tabular}

${ }^{1}$ Beef value per kilogram of live weight was the average obtained by sampling 4 public livestock markets that reported Holstein heifer values across a full range of ages during the same calendar month. 
with an oversupply of replacements relative to anticipated needs. Some producers are maintaining status quo, with the hope that market conditions for replacement heifers will improve. Others are working to identify heifers predicted to be of lower value to their herds and attempting to market them either to other dairies or into the beef market. However, the culling of excess replacement heifers raises the following questions: which heifers should be culled; at what age should they be culled; and what will be the cost compared with the value of removing more inferior animals from the replacement pool?

One approach might be to use genomic testing to identify the heifers of lowest predicted value and to remove them as soon as possible. However, this approach does not consider the effects of disease that might occur during the raising process, and it is reasonable to assume that health issues such as bovine respiratory disease might negatively affect future performance. Unfortunately, inconsistencies in disease definitions, detection challenges, culling biases, and failure to completely record clinical disease in on-farm records lead to inconsistencies in the future measurable effects of bovine respiratory disease, whether identified via clinical signs or via thoracic ultrasound (Bach, 2011; Stanton et al., 2012; Adams and Buczinski, 2016; Teixeira et al., 2017). Thus, culling of heifers on the basis of reported disease alone can be problematic.

Soberon and Van Amburgh have reported an association between higher rates of preweaning daily gain and subsequent milk production (Soberon et al., 2012; Soberon and Van Amburgh, 2013). The exact reasons for this positive correlation are likely multifactorial, but it might be the result of epigenetic programming, less clinical disease, associations between higher feed intake and higher daily gain, or potential advantages in feed efficiency, all of which would likely be associated with higher milk production as adults.

One solution to help avoid the problems associated with the use of clinical disease as a determinant for culling might be to use rate of gain, coupled with some measure of genetic potential. Assuming that consistent points in the growing process are used and accurate weights are recorded, daily gain data are more objective than reliance only on recorded clinical disease and should aid in the identification of potential cull candidates. Frame growth or height is also important but less useful for early culling decisions due to lower expected variation among heifers and greater error potential in the data capture. To evaluate the feasibility of using a weight-based growth approach, a retrospective analysis was performed using the growth and performance records from 2 large dairies (hereafter referred to as herds MW and WC). Holstein replacement heifers born in
2013 from each of the 2 dairies were the population of interest. To be included in the data set, each heifer had to have a sire index-based predicted transmitting ability for milk (PTAM) estimate, birth weight, weaning weight, and grower weight. Although genomic test results would likely prove to be more valuable than relying on sire-based PTAM, neither of the 2 herds were using genomic testing. Weaning weights were recorded during the ninth, tenth, or eleventh week of life and then adjusted by DairyComp 305 to a standardized daily gain at $61 \mathrm{~d}$, called current daily gain 2 (CDG2). Similarly, weights were also recorded between 90 and $105 \mathrm{~d}$; the grower weight estimate was the adjusted estimate for $91 \mathrm{~d}$ and was used to estimate current daily gain 3 (CDG3).

Quartiles for CDG2 and PTAM were calculated for each dairy after removing any heifers that died or that were removed by the farm. If a surviving heifer was in the lower quartile for her herd in both CDG2 and PTAM, she was identified as a performance cull after weaning (wean cull). Since this exercise was performed retrospectively using records only, no heifers were actually culled at this time but instead were identified for future evaluation to determine the potential value of this approach. The process was repeated a second time using CDG3 and PTAM to identify performance cull candidates at the grower phase (grower cull) after removing any heifer that had been culled already by the farm and "removing" the previously identified wean cull candidates. The ANOVA models were built for each herd with projected 305-d milk yields (305M) as the outcome of interest and birth month, age at first calving (days), age at first calving squared, month of calving, and performance cull (yes/no) as explanatory variables. The resulting least squares means $305 \mathrm{M}$ value predicted for a representative heifer within each performance cull group was the value of interest.

Culling a subset of heifers is costly because the revenue received by marketing inferior animals, whether via sales for dairy replacement purposes or for feeder cattle, is less than the cost incurred to raise the heifers to the point of removal, at least in the current dairy economy. This added cost is shifted onto the heifers that survive to calving, reflecting an increase in their net raising cost. Additionally, to the extent that fixed costs exist in the heifer raising program, culling some heifers early will add some fixed cost to the remaining heifers, as the fixed costs will now be diluted over fewer animals.

To evaluate the effect of timing of culling, 3 culling scenarios were created. First, heifers identified as wean culls were removed at 2.5 mo of age. The second scenario included the previous culling option at 2.5 mo plus the selling of heifers identified as grower culls during the 
grower phase. These grower culls were sold at $4.5 \mathrm{mo}$ of age. The final scenario evaluated was similar to the second, except the timing of the selling of the grower culls was delayed until $45 \mathrm{~d}$ before calving (springer culls) to evaluate the potential economic effect of delayed marketing on the cost versus benefit. Thus, for scenarios 2 and 3,2 sets of heifers were removed. For each of these scenarios, the baseline cost per surviving heifer of $\$ 2,016$ (Table 3) was adjusted to reflect the results of culling heifers.

With appropriate selection pressure, the average production per heifer retained was higher than that of the original population containing culled and retained heifers. The benefit of this increased productivity was calculated as the net present value (NPV) of the additional least squares means $305 \mathrm{M}$ for heifers that were retained, compared with that of the baseline population containing both retained and culled heifers, and accounts for increased feed requirements to support the additional or marginal milk. When estimating the value of marginal milk, maintenance feed requirements are ignored because they do not change with increasing milk production. The incremental feed intake required to support the additional milk is dependent upon the energy density of the cow's total ration and the energy required to support the production of the extra milk and its components, assuming that protein levels in the TMR are adequate. A milk to feed DM value of 2.36 (i.e., $2.36 \mathrm{~kg}$ of milk per $1 \mathrm{~kg}$ of DM feed) was used, assuming a total ration energy density of $1.72 \mathrm{Mcal}$ of $\mathrm{NE}_{\mathrm{L}}$ per kilogram of feed DM and an energy requirement of 0.73 Mcal of $\mathrm{NE}_{\mathrm{L}}$ per kilogram of marginal milk. The NPV estimate was for the total marginal milk value over the projected lifetime of the animals, assuming a $39 \%$ herd turnover, a $6 \%$ interest rate, a milk value of $\$ 0.40 / \mathrm{kg}$, a feed cost of $\$ 0.24 / \mathrm{kg}$ of DM, and projected increases in $305 \mathrm{M}$ that occur with increasing parities. For the baseline evaluation, the predicted NPV at calving was set to a value equal to the predicted cost of raising, $\$ 2,016$; thus, the net of the baseline raising cost plus predicted initial NPV is zero by design. In each of the 3 performance cull scenarios, the increased cost per heifer calving was compared with the increased predicted NPV per heifer calving. A positive net benefit means that the increase in NPV exceeded the increase in raising cost. A negative net benefit means that the increase in NPV due to culling was not sufficient to cover the additional raising cost incurred due to culling, resulting in a net cost.

\section{RESULTS}

Each herd was analyzed individually, using the growth and genetic values for heifers born in 2013 (n
$=1,179$ for herd $\mathrm{MW}$ and $\mathrm{n}=2,138$ for herd $\mathrm{WC}$ ). The lower quartile cut points varied by herd and by stage, and herd MW's values were higher than those of herd WC at both evaluation points. At the weaning evaluation, the values were $0.75 \mathrm{~kg} / \mathrm{d}$ CDG2 and 25 $\mathrm{kg}$ PTAM, versus $0.66 \mathrm{~kg} / \mathrm{d}$ and $12 \mathrm{~kg}$, whereas at the grower evaluation the values were $0.78 \mathrm{~kg} / \mathrm{d}$ CDG3 and $121 \mathrm{~kg}$ PTAM, versus $0.69 \mathrm{~kg} / \mathrm{d}$ and $106 \mathrm{~kg}$, respectively, as shown in Table 5. Using these cut points as previously described resulted in differences in productivity in the first lactation between the heifers deemed performance culls and those retained. In herd MW, 87 heifers $(7.4 \%)$ met the criteria for wean culls, and the $305 \mathrm{M}$ of these heifers was $571 \mathrm{~kg}$ less than that of those designated to keep (8,828 vs. $9,400 \mathrm{~kg})$. However, the key value is how much the new, net performance in the retained population improved relative to the original baseline population. In the case of herd MW, the net effect was a gain of $43 \mathrm{~kg}$ in the first lactation $(9,400$ vs. $9,357 \mathrm{~kg})$. Similarly, in herd WC, $151(7.1 \%)$ were wean culls, and their $305 \mathrm{M}$ was $422 \mathrm{~kg}$ less than that of the heifers to keep (8,703 vs. $9,125 \mathrm{~kg}$ ), with a net increase of $29 \mathrm{~kg}(9,125 \mathrm{vs} .9,096 \mathrm{~kg})$. At the grower evaluation, $78 \mathrm{MW}$ heifers $(7.1 \%)$ met the criteria, but the magnitude of the milk difference between groups was lower at $287 \mathrm{~kg}(9,147$ vs. $9,433 \mathrm{~kg})$, and the net was $20 \mathrm{~kg}$. Herd WC's grower evaluation yielded only $78(3.9 \%)$ additional culls, and the difference between groups was greater at $507 \mathrm{~kg}(8,636$ vs. $9,143 \mathrm{~kg})$ but resulted in a similar net of $20 \mathrm{~kg}$.

To better understand the cost versus value of this management decision, the baseline raising model was modified to account first for the removal of the wean culls alone, then for the grower culls in addition to the wean culls, and, finally, for wean culls and grower culls but delaying the removal of the grower culls until just before expected parturition. The baseline cost of raising a heifer without any performance culling was $\$ 2,016$, and each of the culling scenarios resulted in a higher cost of raising per heifer calving, as shown in Table 6 . The lowest raising cost for both herds was for scenario 1 , which had the lowest number of heifers removed (7.4 and $7.1 \%$ for herds MW and WC, respectively), and the culling was done at the youngest age $(2.5 \mathrm{mo})$. The highest raising cost for both herds was for scenario 3 , where 14.5 and $11 \%$ of heifers were performance culled from herds MW and WC, respectively, and the marketing of the grower culls was delayed until $22 \mathrm{mo}$, as opposed to selling them at 4.5 mo. Under previous market conditions, when prepartum heifers held a higher value relative to market cattle values, this scenario resulted in a lower increase in raising cost than did the second scenario. However, current market conditions do not favor this approach. 
The delayed marketing scenario resulted in the largest loss of the 3 tested, but other considerations that were not evaluated could affect the magnitude of the predicted losses. Removing animals at 4.5 mo might result in healthier, faster-growing heifers from that point onward to calving if it leads to reduction in stocking density. Delaying the selection of grower culls from 4.5 mo until 22 mo might improve the accuracy of the selection, and delaying the marketing of the second round of performance culls until 22 mo might be used as a risk-management tool in case replacement needs increase unexpectedly.

Some producers are currently testing heifers at birth and culling genetically inferior calves as soon as test results are available. This approach might lessen the culling loss more than any of the approaches tested here, but it carries significant risk depending on the size of the projected heifer supply. The highest mortality risk for dairy heifers is typically in the preweaning period, and significant disease challenges often occur during this time. Culling heifers before weaning and before growth and health results can be evaluated might save on initial culling losses, but it might also lead to the retention of heifers with significant health challenges if the resulting supply leads to an insufficient number of replacements.

Culling of heifers just past weaning resulted in the best predicted net value among the scenarios tested here. Each herd improved the quality and NPV of heifers at calving by the application of this culling approach but still experienced a net loss, because the benefit created by keeping better-quality heifers was insufficient to overcome the extra raising cost associated with culling the poorer-quality heifers at a loss. The raising costs increased by $\$ 46$ and $\$ 44$ for herd MW and WC, respectively, but the NPV increases were only
$\$ 34$ and $\$ 24$, resulting in a net loss of $\$ 12$ and $\$ 20$ per final heifer calving. However, this selective approach does result in a lower loss than does blindly or haphazardly culling heifers. Given current market conditions, culling excess heifers sooner appears to be the most economical option; however, that might not be the case if culling later allows better identification of potentially inferior animals or if market values for prepartum heifers rebound significantly. Although the results in Table 6 suggest that none of the culling strategies improved the economic returns in this example, it is important to recognize that the returns are dependent upon the market conditions and assumptions used. For example, when the beef value of culls increases, results can change considerably. Thus, this analysis should be viewed as a framework for evaluating heifer culling decisions and not as a definitive answer. A major question that was not addressed here is whether the loss is still better than keeping the excess heifers and either overstocking milk cow facilities or prematurely culling cows.

\section{CONCLUSIONS}

Many dairy farms are struggling with the issues of too many heifers in inventory and how to predict future needs. Herd turnover and dairy replacement needs mirror each other, and failing to keep enough heifers will likely result in lower herd turnover and lost opportunities due to prolonged retention of cows that should be culled. Conversely, producing a large excess of heifers is also costly, but raising a modest excess of heifers over anticipated needs can be viewed as a form of risk management or "insurance" that sufficient replacements will be available in the future. Heifer metrics from birth through the growing and breeding phases and ultimately to subsequent calving reflect losses

Table 5. Modeled growth, genetic, and production differences between heifers from 2 herds (MW and WC) following evaluation based on daily gain and predicted transmitting ability for milk (PTAM)

\begin{tabular}{|c|c|c|c|c|c|c|}
\hline Item & \multicolumn{3}{|c|}{ Herd MW } & \multicolumn{3}{|c|}{ Herd WC } \\
\hline No. of heifers & 1,179 & 1,092 & $87(7.4 \%)$ & 2,138 & 1,987 & $151(7.1 \%)$ \\
\hline Current daily gain $2,{ }^{1} \mathrm{~kg} / \mathrm{d}$ & 0.86 & 0.87 & 0.70 & 0.75 & 0.77 & 0.57 \\
\hline PTAM, kg & 127 & 147 & -129 & 151 & 170 & -105 \\
\hline $305 \mathrm{M}^{2}$ in first lactation, $\mathrm{kg}$ (LSM) & 9,357 & 9,400 & 8,828 & 9,096 & 9,125 & 8,703 \\
\hline Current daily gain $2, \mathrm{~kg} / \mathrm{d}$ & 0.91 & 0.92 & 0.74 & 0.77 & 0.77 & 0.64 \\
\hline PTAM, kg & 147 & 162 & -42 & 170 & 179 & -52 \\
\hline 305M in first lactation, $\mathrm{kg}$ (LSM) & 9,413 & 9,433 & 9,147 & 9,123 & 9,143 & 8,636 \\
\hline
\end{tabular}

${ }^{1}$ Weaning weights were recorded during the ninth, tenth, or eleventh week of life and then adjusted by DairyComp 305 to a standardized weaning weight at $61 \mathrm{~d}$, called current daily gain 2 .

${ }^{2} 305 \mathrm{M}=305$-d milk yield. 


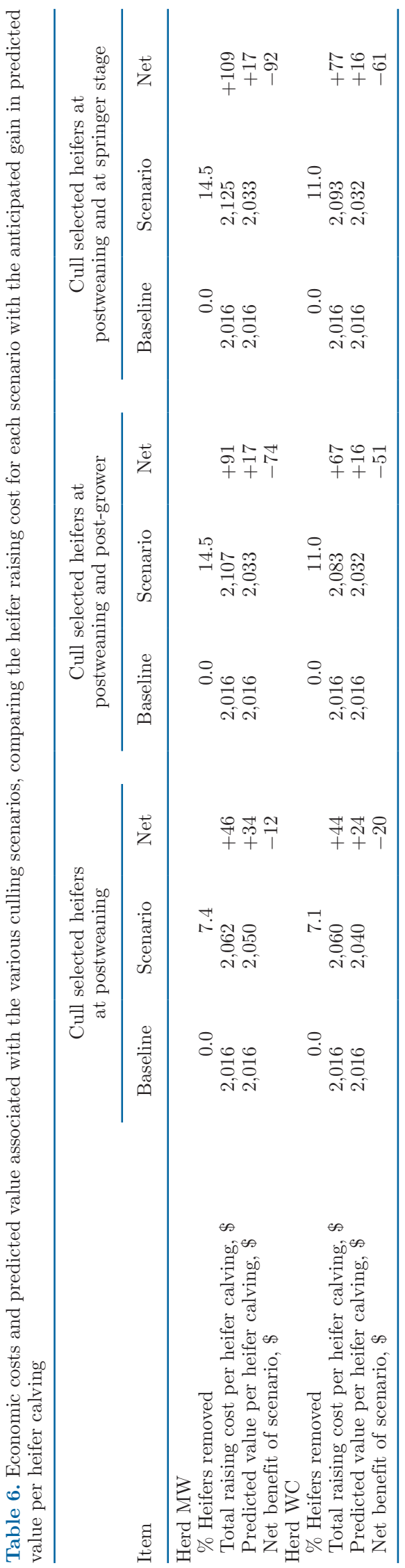

along the entire replacement timeline and can aid in the planning process. In the 50-herd data set, heifers in inventory comprised $102 \%$ of the average milking and dry population across all herds. Actual heifer needs will vary by herd based upon heifer management and anticipated herd turnover. Given the current market conditions, culling excess heifers results in a loss relative to the raising costs, regardless of whether culling occurs at $2.5,4.5$, or 22 mo of age, but this project did not address the potential costs of failure to cull. However, careful selection to identify predicted low performers can lessen this heifer culling loss, and under the assumptions used here, earlier culling resulted in lower losses. However, the exact cost versus value of a selective culling program will vary based on cost inputs of newborn calf values and key determinants of raising costs, as well as on market values for culled heifers.

\section{ACKNOWLEDGMENTS}

The authors have not stated any conflicts of interest.

\section{REFERENCES}

Adams, E. A., and S. Buczinski. 2016. Short communication: Ultrasonographic assessment of lung consolidation postweaning and survival to the first lactation in dairy heifers. J. Dairy Sci. 99:14651470. https://doi.org/10.3168/jds.2015-10260.

Bach, A. 2011. Associations between several aspects of heifer development and dairy cow survivability to second lactation. J. Dairy Sci. 94:1052-1057. https://doi.org/10.3168/jds.2010-3633.

De Vries, A., M. Overton, J. Fetrow, K. Leslie, S. Eicker, and G. Rogers. 2008. Exploring the impact of sexed semen on the structure of the dairy industry. J. Dairy Sci. 91:847-856. https://doi.org/10 $.3168 /$ jds.2007-0536.

Everett, R. W., J. F. Keown, and E. E. Clapp. 1976. Production and stayability trends in dairy cattle. J. Dairy Sci. 59:1532-1539. https: //doi.org/10.3168/jds.S0022-0302(76)84399-8.

Fetrow, J., K. V. Nordlund, and H. D. Norman. 2006. Invited review: Culling: Nomenclature, definitions, and recommendations. J. Dairy Sci. 89:1896-1905. https://doi.org/10.3168/jds.S0022 -0302(06)72257-3.

Fetrow, J., M. Overton, and S. Eicker. 2007. Sexed semen: Economics of a new technology. Pages 39-60 in Proc. 8th Western Dairy Management Conference, Reno, NV, March 7-9, 2007.

Hadley, G. L., C. A. Wolf, and S. B. Harsh. 2006. Dairy cattle culling patterns, explanations, and implications. J. Dairy Sci. 89:22862296. https://doi.org/10.3168/jds.S0022-0302(06)72300-1.

Karszes, J. 2014. Dairy replacement programs: Costs and analysis, 3rd quarter 2012. Cornell Pro-Dairy White Paper EB 2014-02. Accessed Jun. 14, 2019. https://ecommons.cornell.edu/bitstream/ handle/1813/36889/DairyReplaceCost12-3.pdf?sequence $=1 \&$ isAllowed $=\mathrm{y}$.

Nieuwhof, G. J., H. D. Norman, and F. N. Dickinson. 1989. Phenotypic trends in herdlife of dairy cows in the United States. J. Dairy Sci. 72:726-736. https://doi.org/10.3168/jds.S0022-0302(89)79166-9.

Overton, M., R. Corbett, and W. Boomer. 2013. An economic comparison of conventional vs. intensive heifer rearing. Pages 122-130 in Proc. Western Dairy Management Conference, Reno, NV, March $6-8,2013$.

Overton, M., and K. Dhuyvetter. 2017. Economic considerations regarding the raising of dairy replacement heifers. Pages 457-474 in Large Dairy Herd Management. 3rd ed. D. K. Beede, ed. American Dairy Science Association, Champaign, IL. 
Soberon, F., E. Raffrenato, R. W. Everett, and M. E. Van Amburgh. 2012. Preweaning milk replacer intake and effects on long-term productivity of dairy calves. J. Dairy Sci. 95:783-793. https://doi .org/10.3168/jds.2011-4391.

Soberon, F., and M. E. Van Amburgh. 2013. Lactation biology symposium: The effect of nutrient intake from milk or milk replacer of preweaned dairy calves on lactation milk yield as adults: A meta-analysis of current data. J. Anim. Sci. 91:706-712. https:// doi.org/10.2527/jas.2012-5834.

Stanton, A. L., D. F. Kelton, S. J. LeBlanc, J. Wormuth, and K. E. Leslie. 2012. The effect of respiratory disease and a preventative antibiotic treatment on growth, survival, age at first calving, and milk production of dairy heifers. J. Dairy Sci. 95:4950-4960. https: //doi.org/10.3168/jds.2011-5067.
Teixeira, A. G. V., J. A. A. McArt, and R. C. Bicalho. 2017. Thoracic ultrasound assessment of lung consolidation at weaning in Holstein dairy heifers: Reproductive performance and survival. J. Dairy Sci. 100:2985-2991. https://doi.org/10.3168/jds.2016-12016.

Tranel, L. 2019. Heifer raising costs in 2019. ISU Publication LT18-01. Accessed Sep. 6, 2019. https://www.extension.iastate.edu/ dairyteam/files/page/files/whats_it_cost_to_raise_heifers_2019 -0.pdf.

\section{ORCIDS}

M. W. Overton () https://orcid.org/0000-0002-5168-6319 